19

\title{
Income Contingent Loans for Higher Education and Beyond
}

María Racionero

The Australian National University, Australia

The role of income contingent loans (ICLs) as a risk-management device is being increasingly emphasized. Many countries have adopted ICLs to finance higher education and alternative uses have been proposed. In this chapter I first outline the main features of existing ICL schemes for higher education and discuss alternative designs. I then identify issues to be addressed when considering novel applications. Many existing ICL schemes for higher education imply large implicit subsidies: the interest rate is often highly subsidised and the shortfall from non-repayment is typically financed from general taxes. Increasing the share of the cost borne by successful graduates could help alleviate the negative consequences of current designs, but the extent to which this is feasible depends on whether there are significant moral hazard and adverse selection effects. These problems have traditionally seemed relatively minor in the higher education context but could be quite significant for some of the proposed applications.

\subsection{Introduction}

Australia was the first country in the world to implement a universal income contingent loan scheme to finance the cost of higher education - the Higher Education Contribution Scheme (HECS) - in 1989. Several countries have adopted similar schemes since then. These include New Zealand in 1992 shortly after Australia and most recently the UK in $2005 .{ }^{1}$ Income contingent loans (hereafter, ICLs) provide insurance against adverse labor market outcomes by making repayments contingent on earned income. In particular, 
they protect low income earners since no repayment is typically due when earnings fall below a minimum income repayment threshold.

The role of ICLs as a more general risk-management device has been increasingly emphasized and, accordingly, there are a growing number of proposals to extend the use of ICLs to other contexts. Chapman (2006a) considered applications of ICLs to drought relief, criminal reparations, provision of finance to economically disadvantaged regions, and support to low-income households. The Australian Journal of Labour Economics devoted in 2009 a special issue to further explore some of these applications and propose novel ones such as mature age training, paid parental leave and innovation, among others. ${ }^{2}$

This chapter is organised as follows. In Section 19.2 I discuss some aspects of existing ICL schemes for higher education and review some of the main results in the literature. In Section 19.3 I identify some of the issues that require in my view careful attention when considering extending the use of ICLs to other contexts. In Section 19.4 I comment on the general theoretical framework proposed by Quiggin (Chapter 3, this volume) and suggest avenues for further research. Finally, I provide some concluding remarks in Section 19.5.

\subsection{ICLs for higher education}

In this section I discuss some aspects of existing ICL schemes for higher education and review some of the main results in the theoretical literature.

\subsubsection{Implicit subsidies}

Many of the existing ICL schemes for higher education imply large implicit subsidies, which stem from the fact that the real interest rate imposed on the loan is often highly subsidised. This is for instance the case of the Australian HECS, where the real interest rate applied to the loan is zero. ${ }^{3}$ As a consequence, students who defer the payment receive larger subsidies the longer it takes them to repay the debt (that is, the net present value of the debt decreases with the time it takes to repay).

These implicit subsidies lack transparency, which is among the desirable characteristics of any public policy. ${ }^{4}$ In addition, they contribute to increase the share of the cost of the loans that falls on the taxpayer. Barr (2012b and Chapter 5, this volume) identifies the cost of loans to the taxpayer as the root of the problem and attributes part of this cost to badly targeted interest subsidies.

Barr claims that interest rates do not help students (graduates make repayments, not students); and they help low-earning graduates only slightly, since they are protected by income contingent repayments and, for graduates with low lifetime earnings, eventual forgiveness' (Barr 2012b, p. 486). He 
argues that in an income contingent scheme higher interest rates increase the duration of the loan, with no effect on monthly repayments, and illustrates, by means of a simple example, how the major beneficiaries of interest subsidies are in fact successful professionals in mid-career. The high cost from bad targeting of interest subsidies is explored in detail in Shen and Ziderman (2009), a study that compares the hidden grants and repayment ratios for 44 loans in 39 countries.

\subsubsection{Who should pay for the shortfall?}

Most of the existing ICL schemes rely on contributions from general taxes to finance the cost of the education of unsuccessful students. This is for instance the case of the schemes in place in Australia and the UK. This type of scheme is often denominated a 'risk-sharing' ICL because the risk is shared with the taxpayer. An ICL in which successful graduates are made responsible for the cost of the education of unsuccessful students is often called a 'risk-pooling' ICL and would typically be self-financing. ${ }^{5}$

There are very few examples of risk-pooling ICLs. One such scheme was implemented by Yale University in 1971: the Tuition Postponement Option program. All students graduating in a given year with an outstanding debt were grouped in repayment cohorts with collective repayment responsibilities: an individual student's contractual obligation concluded only when his or her cohort repaid the aggregate loan balance, or after 35 years. The discontinuation of the Yale Plan was partly attributed to adverse selection: Nerlove (1975) argued that, for such a university, hoping to attract the highest quality students, the scheme had the perverse effect of encouraging those students who expected to be successful in the labor market to seek enrolment at universities offering non-ICL financial assistance. This conveyed the idea that self-financing schemes were not feasible.

However whether risk-pooling schemes induce adverse selection depends crucially on the availability of attractive funding alternatives, and hence on the degree to which the scheme is sufficiently universal and/or compulsory. In 2001 Hungary first implemented a broad-based self-financing ICL. ${ }^{6}$ Proposals such as repayment extensions and surcharges, like those put forward by Barr (2010), would impose a larger share of the cost on successful graduates, and can be interpreted as introducing a certain degree of risk-pooling.

García-Peñalosa and Wälde (2000) and Del Rey and Racionero (2010) analyse higher education participation under several alternative financing schemes, including tax-subsidy and mortgage-type loans alongside risksharing and risk-pooling ICLs. ${ }^{7}$ In García-Peñalosa and Wälde (2000) individuals differ in inheritance whereas in Del Rey and Racionero (2010) they differ in ability. When individuals differ in ability it is possible to compute an optimum ability threshold (that is, an optimal level of 
participation in higher education) and study whether the alternative schemes induce insufficient or excessive participation.

Del Rey and Racionero (2010) identify the subsidy and insurance components of the different schemes considered and show that when risk aversion is sufficiently large the risk-pooling ICL, which provides more insurance, yields higher participation. ${ }^{8}$ Participation remains inefficiently low however because none of the higher education financing schemes considered provides full insurance at actuarially fair prices. They propose an alternative financing scheme that induces optimal participation by fully insuring the lowest ability individual who should enrol in higher education, and show that this scheme is equivalent to a risk-pooling ICL that covers both financial costs of education and forgone earnings.

\subsubsection{Extending the loan beyond tuition fees?}

Existing ICL schemes for higher education differ in what is covered by the loan: for example, in Australia the loan only covers tuition fees while in New Zealand and the UK the loan can also be used to finance living expenses. Insufficient finance can represent a significant impediment for academically deserving but cash constrained individuals to pursue higher education. Higgins (2011) shows that in Australia, despite changes aimed at improving the financial situation of university students, financial hardship remains prevalent and the rates of paid student employment are relatively high. According to the Universities Australia 2006 survey of undergraduates about 70 per cent of undergraduate students worked during the semester, at an average of almost 15 hours, and over 40 per cent of full-time undergraduates (and 50 per cent of part-time undergraduates) reported a significant negative effect on their academic experience as a consequence.

Higgins (2011) estimates that as little as AUD \$1,500 per annum could result in improved participation and educational outcomes for many existing and prospective students. He examines the case for extending ICL to income support under two alternative scenarios - a loan surcharge and real loan indexation - and argues that a surcharge would be more attractive to students, and cross-subsidisation from higher earning to lower earning graduates would reduce the cost to the taxpayer.

An extension of the ICL to income support using a risk-pooling mechanism would be in line with the theoretical results mentioned in Section 19.2.2. In 2010 the Australian government introduced Start-up Scholarships, which amounted to $\$ 2,050$ per annum in 2013 , to help with the living costs for eligible students. In April 2013 it was announced that from 1 January 2014 the Start-up Scholarships would be replaced by Start-up Loans to be repaid in an income contingent manner following the existing Higher Education Loan Program (HELP) parameters (that is, risk-sharing rather than risk-pooling). 


\subsubsection{Moral hazard and adverse selection effects in higher education?}

One of the main features of ICLs is that, by making repayment contingent on earned income, they provide insurance. Moral hazard and adverse selection are however two well-known problems associated with the provision of insurance when there is asymmetry of information. The moral hazard problem stems from the fact that the insured-against event may happen more often when the insurer is unable to observe the effort of the insuree because, due to insurance, the insuree has less incentives to avoid the risky outcome. The adverse selection problem concerns the fact that an insurer unable to observe the risk type of the insurees may end up trading more often with the most risky individuals, who are those that stand to gain more from insurance.

Self-financing schemes such as risk-pooling ICLs, which make successful graduates bear a larger share of the cost of higher education, can arguably affect their willingness to exert effort. Risk-pooling may also affect the willingness of students who expect to be successful to take such a loan if they have alternative funding options. A risk-sharing ICL that relies partly on tax revenues for the cost of education of unsuccessful students could be viewed as a compromise between pure mortgage-type loans, with no taxpayer contributions and no insurance, ${ }^{9}$ and risk-pooling ICLs, with no taxpayer contributions but a certain degree of insurance, even if as illustrated in Del Rey and Racionero (2010) it falls short of providing full actuarially fair insurance.

The extent to which moral hazard and adverse selection are indeed relevant problems in the context of higher education deserves further investigation. Palacios (Chapter 17, this volume) argues that agency costs are not as high as typically thought when dealing with students. He uses a simple dynamic example to illustrate that, when present effort affects future earnings, the effect of moral hazard is likely to be smaller than often considered. The cost of shirking today increases when the individual takes the loss in future earnings into account, and this reduces the distortion associated with the income contingent contract. He acknowledges that income contingent contracts may be more distortionary when future earnings do not depend on current effort, or when the expected work life of the individual is relatively short. However, the impact that current effort has on future earnings is likely to be more significant for young graduates, making them less prone to moral hazard. He also claims that adverse selection effects may be less important when students do not perfectly know their own ability.

\subsubsection{Political economy aspects of switching between schemes}

Ultimately whether a particular higher education financing scheme is implemented depends to a large extent on whether it can gather sufficient political support. The level of support in turn often depends on the comparison of the proposal with the scheme in place. A few recent 
contributions have explored the political economy of higher education finance in frameworks that include ICLs as options. Borck and Wimbersky (2009) study voting over a relatively comprehensive set of higher education financing schemes in an economy where risk-averse households differ only in wealth. Del Rey and Racionero (2012a, 2012b) consider risk-averse individuals who differ both in ability and wealth and focus on the choice between two financing schemes at a time to illustrate the tensions countries face when attempting to switch between schemes.

Del Rey and Racionero (2012a) analyse the choice between tax-subsidy and risk-sharing ICLs to capture the situation of countries that have traditionally financed higher education from general taxation and consider increasing students' contributions through partially subsidised ICLs. Many Western European countries have experienced, or are considering, this type of reform. ${ }^{10}$ In their simple framework there is an ability threshold below which individuals prefer the risk-sharing ICL and above which they prefer the taxsubsidy scheme. The composition of the groups and the final voting outcome depends however on the comparison of this ability threshold with the ability thresholds that determine participation under each financing scheme.

Risk aversion plays a key role: an increase in risk aversion reduces participation and hence support for the tax-subsidy, since those who do not study unambiguously prefer the ICL; in addition, if the college premium is large a larger degree of risk aversion increases support for ICLs among some students - those with relatively lower ability and wealth. Two types of support patterns are possible, and both are shown to arise in numerical illustrations: either the support for the tax-subsidy comes from those who study regardless of the scheme in place, and some - those with relatively higher ability and wealth - who study with tax-subsidy but not with ICLs; or the support for the tax-subsidy scheme comes exclusively from only some individuals - those with relatively higher ability and wealth - who study regardless of the scheme in place. The higher probability of success of higher ability individuals induces them to support the tax-subsidy instead of ICLs because they expect to contribute more under the latter; the lower absolute risk aversion of wealthier individuals reduces their demand for schemes that provide insurance, and hence their support for ICLs. However, when the degree of risk aversion is particularly large ICLs become relatively more attractive.

Del Rey and Racionero (2012b) focus alternatively on the choice between risk-sharing and risk-pooling ICLs to capture the situation faced by countries considering switching from partly subsidised to mostly self-financed funding schemes, while still providing insurance through income contingent repayments. ${ }^{11}$ They show that larger degrees of risk aversion imply increased support for the risk-pooling ICL. In their numerical illustration the riskpooling ICL is preferred by a majority for all the combinations of parameter values considered. 
These results cast a positive light on policy recommendations for full recovery of loans in an income contingent fashion, such as the repayment extensions and surcharges proposed by Barr (2010) in order to increase the burden on successful graduates and reduce the burden on the taxpayer. The cost to the taxpayer compromises in Barr's view the objectives of (better) quality, (wider) access and (larger) size.

A problem of risk-pooling schemes is that they may lead to adverse selection when alternative funding arrangements are available: high-ability individuals may want to opt out because, with higher probabilities of success, they are likely to be the ones made responsible for the cost of education of unsuccessful students. One solution is to make risk-pooling schemes compulsory but this might not be enforceable when students are mobile and can seek alternative, more favourable, funding arrangements elsewhere.

Del Rey and Racionero (2012b) explore the possibility of letting students self-select into two schemes: a self-financing ICL and a pure loan, where the latter is more attractive to wealthy high-ability individuals. In essence, the government offers loans to students and lets them choose whether to have them insured in a risk-pooling fashion or not insured at all. They show that risk-pooling ICLs can be guaranteed without resorting to coercion. If risk aversion is sufficiently large the possibility of opting out becomes less attractive and the participation pattern is then similar to that obtained when only risk-pooling ICLs are offered: the extra cost successful graduates bear, above the cost of their own education, can be interpreted as the risk premium they are willing to pay for the insurance risk-pooling schemes provide.

\subsection{Novel applications}

Chapman and Hunter (2009) briefly discuss some alternative applications of ICLs to contexts such as drought relief, paid parental leave and mature aged training, among others. These proposals are explored in further detail in the papers of the special issue of the Australian Journal of Labour Economics. In the concluding piece of the special issue Gregory (2009) highlights the reasons that in his view made the introduction of HECS so successful: in particular, he mentions that there wasn't any sufficiently attractive alternative at the time, and that adverse selection and moral hazard problems seemed relatively minor in this particular context. Many of the novel proposals may however be more prone to moral hazard and adverse selection effects, and in many cases there are existing - even if imperfect, still attractive to many alternatives in place.

\subsubsection{Tackling adverse selection and moral hazard}

When moral hazard and adverse selection effects matter, addressing them affects the design of the policy. To fight the moral hazard effects associated 
with the provision of insurance, governments typically use deductibles, copayments and/or co-insurance, which are designed to increase the individual's exposure to risk and induce him or her to exert more effort to avoid the insured-against event. To tackle adverse selection effects, governments often employ discriminatory rules, in the form of menus that include different policies for different types. These menus are designed to induce individuals to reveal their types by their choice and typically involve distortions being imposed on particular types. These solutions can render the policies complex and costly to administer.

It is worth exploring whether the costs of addressing moral hazard and adverse selection problems are small enough or too large to make a particular proposal worth pursuing. To a certain extent this is an empirical issue. However, a sound theoretical framework can help to identify the parameters of interest. It can also help to explain why, when asymmetry of information is an issue, a policy feature that seems counterintuitive may indeed be optimal. ${ }^{12}$

Chapman and Higgins (2009) explore an optional ICL supplement to paid parental leave, beyond the 18 weeks taxpayer funded scheme announced by the Australian government in $2009 .{ }^{13}$ This study provides a good illustration of the complexities an ICL scheme has to contend with when moral hazard and adverse selection effects are significant. The authors indeed recognise that moral hazard and adverse selection may be critical policy issues in the context of paid parental leave and highlight how they are addressed in the scheme design. Solutions put forward to fight moral hazard and adverse selection problems include, among others, restricting loan duration and size, restricting eligibility to parents with workforce attachment, reducing minimum repayment thresholds to those below used for HECS, and making the debt an obligation of both parents.

\subsubsection{Existing policies and political support}

For many of the novel applications of ICLs explored in the special number of the Australian Journal of Labour Economics there is an existing policy already in place. In some cases the proposed scheme seeks to replace the existing policy. In other cases, such as the paid parental leave extension explored in Chapman and Higgins (2009), the purpose is to supplement, not replace, another policy. In cases where the ICL is conceived as a supplement, it is crucial to understand whether individuals correctly perceive it as such or believe on the contrary that the existing support may be removed or reduced upon the introduction of the ICL, as this will significantly affect the political support for such a proposal.

Higgins and Withers (2009) examine the community views on HECS and on ICLs more broadly, including several of the novel applications. The survey results indicate strong community support for HECS, an ICL for Research and Development, and repayment of government assistance to elite athletes while 
opinion on repayable assistance to farm businesses for drought relief is more evenly distributed. They find however little support for introducing an ICL scheme for child care, and especially so from those who have received government assistance for child care in the past. With respect the ICL scheme for child care, the authors remark that responses would have substantially differed if the question had instead indicated that the ICL was intended to supplement, rather than replace, the existing government benefit. They acknowledge that this deserves further investigation.

\subsubsection{Accumulation of ICL debts}

An accumulation of individual and/or family ICL debts is likely to result if several ICL proposals are implemented and individuals are allowed to apply for more than one. Such a situation would for instance arise if a couple of young graduates, with outstanding HECS debts, have children and obtain an ICL for parental leave support.

ICLs are designed with the twin objectives of consumption smoothing and default insurance. In order to continue to honour these objectives the overall repayment schedule, if several ICLs are simultaneously offered, should remain manageable from the individual's perspective: that is, the combination of repayment thresholds and repayment rates should remain sufficiently generous to avoid inflicting financial stress to individuals with more than one ICL. However, the government would need to carefully design the ICL policies, taking the full set simultaneously into account, to ensure that the cost to the taxpayer does not escalate. Risk-pooling ICLs that charge real interest rates are better suited to accomplish this since they impose a smaller burden, if any, on the taxpayer.

\subsubsection{Compensation versus responsibility}

The use of ICLs is often justified on efficiency grounds: ICLs help overcome capital market imperfections in instances where risk and uncertainty place important limits to what can be achieved by traditional loans.

Many existing ICL schemes for higher education impose however a significant burden on the taxpayer. This is particularly so when the real interest rate is highly subsidised and/or the debt of unsuccessful individuals is mostly financed out of general taxes. Many of the novel applications of ICLs address problems that affect subsets of the population, such as farmers, parents or mature students. If the design of the ICL implies substantial subsidies, and hence redistribution, to a particular group I believe that a detailed explanation of why that group receives a favourable treatment is necessary.

There is a strand in the social choice literature devoted to understanding how compensation and responsibility arguments shape public policies. When individuals differ in several characteristics, it may be deemed that they 
deserve compensation for some of the differences, for which they are not responsible, but not so for other differences, for which they are held responsible. Fleurbaey (2008) notes that risk and insurance issues complicate the analysis of compensation and responsibility: when individuals take risks and are especially unlucky it seems harsh to consider that they should bear the full consequences of their behavior. One solution, proposed for instance by Le Grand (1991), essentially implies making all those undertaking a risky activity pay a special tax to fund the indemnity to the unlucky ones among them.

If individuals are held responsible for their decision to belong to a certain category (that is, they choose to become farmer, parent or student) but these decisions involve risks, the planner should then focus on providing insurance in the most efficient way possible. The optimal design of the insurance policy will depend on the particular circumstances in the market, and very importantly on the extent of adverse selection and moral hazard effects of insurance, but the argument above suggests risk-pooling ICLs should be preferred when feasible. If there are significant public benefits stemming from the individual decisions it may be possible to justify providing subsidies, alongside insurance, preferably transparent and commensurate with the value of the public benefit. ${ }^{14}$

\subsection{Towards a general theoretical framework}

In Chapter 3 of this volume, Quiggin proposes a theoretical framework that seeks to be sufficiently general to embed a diverse set of ICL applications. In a model where individuals have identical preferences, differ only in ability and face wage uncertainty, he compares ICLs to both market loans and taxfinanced public subsidies. This comparison is particularly relevant in the presence of asymmetric information and the possibility of default. He concludes that, under reasonable circumstances, ICLs are superior to either of the alternatives considered.

When compared with tax-financing, ICLs are more equitable when the initial transfer is positively correlated with wages. ICLs can also be more efficient: this is the case when the individual expects to repay the loan in full. When compared with market loans, ICLs provide insurance against wage uncertainty. Quiggin notes that 'adverse effects on labor market efficiency only arise for wages in the interval where the optimal effort, given the repayment schedule, would lead to partial, but not complete, repayment.' (p.46)

The model aims to remain sufficiently general to be able to serve as the basis for the analysis of different ICL proposals. It would be worthwhile exploring how the general conclusions adapt to particular ICL applications. For instance, it seems worth exploring how large the wage interval for which adverse effects on labor arise is, and also how the distortion on labor 
compares with the gain from default insurance. Numerical simulations calibrated to represent particular ICL proposals could shed more light on the extent to which the labor supply distortions are small enough, and the gains from default protection are large enough, to support the ICL proposal.

In the context of higher education, and concerning the comparison between mortgage-type repayment loans and alternatives, including income contingent options, Felicia Ionescu has published a series of papers that seek to quantify the welfare effects of different policy options on individuals of different characteristics, taking into consideration how these options affect a series of individual decisions including the decision to default, the decision to participate, the choice of consolidation regime, and so on (see Chatterjee and Ionescu (2012), Ionescu (2008), Ionescu (2009) and Ionescu (2011) for details on the modeling strategy and the main outcomes). These papers could provide a good basis to undertake further analysis of the kind within the present framework.

The model proposed by Quiggin (Chapter 3, this volume) shares a few common features with models employed in the so-called 'new dynamic public finance' literature. ${ }^{15}$ Contributions in this field emphasize the roles of risk and time: taxpayers typically face a sequence of uninsurable shocks to the value of their human capital. It may be worth exploring the links to some of the contributions in this literature. In particular, Andenberg (2009) examines the optimal design of education and redistributive policies in an environment where individuals invest in education and face idiosyncratic wage risk. A key feature of human capital investments is whether they increase or decrease wage risk. He shows that this feature alone determines whether a constrained optimal allocation should be characterized by a positive or a negative education premium. One key limitation of his framework is that individuals are ex-ante identical.

Findeisen and Sachs (2012) consider both ex-ante heterogeneous individuals and risky educational investments. They study the optimal combination of income tax and education policies in a dynamic asymmetric information environment with heterogeneous agents and uncertainty, where both education and labor supply decisions are endogenous. They show that the Pareto-optimal labor distortions are history-dependent: the implicit tax rates depend on education in addition to income. The Pareto-optimal allocation can be implemented by simple policy instruments: income contingent student loans in addition to standard taxes on labor earnings and savings.

\subsection{Concluding remarks}

This chapter includes some insights on existing ICL schemes for higher education, the novel applications of ICLs to other contexts and the general theoretical framework proposed by Quiggin in Chapter 3. 
Existing ICL schemes for higher education impose a large share of the cost on the taxpayer. This can significantly harm access, quality and size. In particular, some existing ICL schemes do not cover income support, which hinders participation. A move towards charging real interest and increasing the share of the cost borne by successful graduates would reduce the cost to the taxpayer and help alleviate some undesirable consequences of existing ICL schemes. The final design is however likely to fall short of complete riskpooling (that is, self-financed cross-subsidisation of unsuccessful students by successful graduates) since the incentives for those who expect to be successful have to be considered, especially if there are relevant informational asymmetries.

The higher education finance experience with ICLs should help in the analysis of a growing number of proposals to extend the use of ICLs to other contexts (for example, drought relief, mature age training and paid parental leave). Moral hazard and adverse selection problems are likely to be more significant in these contexts. It is worth exploring whether the costs of addressing moral hazard and adverse selection are small enough or too large to make a particular proposal worth pursuing, when for many of these proposals there are alternative, relatively attractive, policies already in place.

To a certain extent this is an empirical question. However, a sound theoretical framework can help to identify the main issues at stake. In Chapter 3, Quiggin proposes a theoretical framework that aims to be sufficiently general to enable the analysis of diverse ICL applications. He compares ICLs to both market loans and tax-financed public subsidies and concludes that, under reasonable circumstances, ICLs are superior to either of the alternatives considered. Further work, such as performing numerical simulations for particular applications and exploring the links to the new dynamic public finance literature, could shed more light on those general results.

\section{Notes}

1. See Chapman (2006b) for an overview of the international experience with income contingent loans for higher education, and Chapman (Chapter 1, this volume) and Barr (Chapter 5, this volume) for some more recent applications.

2. See Chapman and Hunter (2009) for a brief overview of the special issue of the Australian Journal of Labour Economics.

3. Those who choose to pay their fees up-front have up to date received a discount, which was originally 25 per cent but was progressively reduced to 10 per cent. The up-front discount means that in effect HECS incorporates an implicit interest rate. The Australian government announced in April 2013 that it plans to abolish the up-front payment discount.

4. The desirable properties of a tax system, and generally any public policy, are efficiency, equity, administrative simplicity and transparency (often also called political responsibility). 
5. There is not yet a consensus on student loan terminology. I employ the terminology from Chapman (2006b) for consistency with my previous contributions (for example, Del Rey and Racionero 2010, 2012a, 2012b). Nicholas Barr, in, for example, Barr (2012a) section 4.1.2, frames the question in terms of where the cost of the loss falls: (a) on the taxpayer, (b) on the cohort of graduates, (c) on universities via a universityspecific risk premium, or (d) on a mix. The risk-sharing and risk-pooling ICLs correspond to (a) and (b), respectively.

6. See Berlinger (2009) for an analysis of the Hungarian scheme.

7. García-Peñalosa and Wälde (2000) do not use the term risk-pooling ICL but the system they describe as graduate taxes resembles the idea of risk-pooling ICL in Del Rey and Racionero (2010).

8. This result is similar to that obtained by García-Peñalosa and Wälde (2000) in a slightly different context.

9. The mortgage-type pure loan scheme with no taxpayer contribution and no insurance should be treated as a benchmark and differs in some respects from the mortgage-type loans that are offered in reality. For instance, in the US student loans have traditionally received interest subsidies and/or been guaranteed by the government, among other concessions. Clearly, in these cases, taxpayers do contribute to the cost of higher education, either by financing the interest subsidy or the default. As highlighted in Ionescu (2008), the default rates were indeed quite large in the late 1980s.

10. Many countries are raising tuition fees and some of them have considered offering ICLs to counterbalance liquidity constraints associated with increased tuition fees. The UK government first introduced tuition fees of $£ 1,000$ per year in 1998, together with loans with income contingent repayments to cover living costs but not fees. In 2006 the UK government extended the ICL cover to tuition fees, which were then allowed to vary up to $£ 3,000$. Reforms in 2012 raised the fees cap to $£ 9,000$ (Barr, 2012b). These fee increases generated some heated protests from students in late 2010 when first proposed.

11. The Australian Budget 2013-2014 papers predict that students will owe the government AUD $\$ 42.1$ billion by the end of the forward estimates in 2016-17. The amount of student debt that will never be repaid to government has increased by close to AUD \$1 billion from 2012 to 2013, to AUD \$6.2bn. Andrew Trounson and Christian Kerr point out in "Lost HECS debt \$6.2bn, and rising" (The Australian, January 21st 2013), that '[t]he rising doubtful debt and forgone interest of the Higher Education Loan Program, most commonly known as HECS, has fuelled a fresh call for the government to look at reining in the cost.'

12. The optimal non-linear taxation framework provides a number of examples of such policy features. For instance, marginal distortions, in the form of positive marginal tax rates, are imposed on low-ability individuals not to raise revenue from them, but to raise revenue from higher ability individuals who then find pretending to be lowability less attractive.

13. Also see Higgins (Chapter 10, this volume) for a summary of the proposal.

14. In the case of the paid parental leave application explored in Chapman and Higgins (2009) the authors note that there may be a case for contributions from taxpayers, employers and parents. The paper however does not dwell on the appropriate balance and focuses instead on how families might be able to finance their own optional extension.

15. Salanié (2011) includes a brief introduction to the new dynamic public finance literature. For a more detailed discussion see Kocherlakota (2010). 


\section{References}

Anderberg, D. (2009) 'Optimal Policy and the Risk Properties of Human Capital Reconsidered', Journal of Public Economics, vol. 93, pp. 1017-1026.

Barr, N. (2010) 'Designing Student Loans to Protect Low Earners', Research Note, Policy Exchange. Online at http://www.policyexchange.org.uk/images/publications/pdfs/ Student_loans.pdf.

Barr, N. (2012a) 'Financing Higher Education: Mobility, Quality and Access', presented at Cross Border Mobility of Students and Researchers: Financing and Implications for Economic Efficiency and Growth, CESifo Venice Summer Institute 2012.

Barr, N. (2012b) 'The Higher Education White Paper: The Good, the Bad, the Unspeakable - and the Next White Paper', Social Policy and Administration, vol. 46, no. 5, pp. 483508.

Berlinger, E. (2009) 'An Efficient Student Loan System: Case Study of Hungary', Higher Education in Europe, vol. 34, no. 2, pp. 257-267.

Borck, R. and M. Wimbersky (2009) 'Political Economics of Higher Education Finance', CESifo Working Paper Series no. 2829.

Chapman, B. (2006a) Government Managing Risk: Income Contingent Loans for Social and Economic Progress (London: Routledge).

Chapman, B., (2006b) 'Income Contingent Loans for Higher Education: International Reforms', in E.A. Hanushek and F. Welch (eds). Handbook on the Economics of Education, vol. 2 (Amsterdam: North-Holland), pp. 1435-1503.

Chapman, B. and T. Higgins (2009) 'An Income Contingent Loan for Extending Paid Parental Leave', Australian Journal of Labour Economics, vol .12, no. 2, pp. 197-216.

Chapman, B. and B. Hunter (2009) 'Exploring Creative Appliances of Income Contingent Loans', Australian Journal of Labour Economics, vol. 12, no. 2, pp.133-144.

Chatterjee, S. and F. Ionescu, F. (2012) 'Insuring Student Loans Against the Financial Risk of Failing to Complete College', Quantitative Economics, vol. 3, no. 3, pp. 393-420.

Del Rey, E. and M. Racionero (2010) 'Financing Schemes for Higher Education', European Journal of Political Economy, vol. 26, pp. 104-113.

Del Rey, E. and M. Racionero, M. (2012a) 'Voting on Income-Contingent Loans for Higher Education', The Economic Record, special issue, vol. 88, pp. 38-50.

Del Rey, E. and M. Racionero (2012b) 'Choosing the Type of Income-Contingent Loan: Risk-Sharing Versus Risk-Pooling', ANU Centre for Economic Policy Research Discussion Working Paper 671. Online at http//cbe.anu.edu.au/researchpapers/dpcepr/choosing-the-type-of-income-contingent-loan-risk-sharing-versus-riskpooling/.

Findeisen, S. and D. Sachs, D. (2012) 'Education and Optimal Dynamic Taxation: The Role of Income Contingent Student Loans', ECON Working Paper 040, Department of Economics, University of Zurich. Online at http://ideas.repec.org/p/zur/econwp/040.html.

Fleurbaey, M. (2008) Fairness, Responsibility and Welfare (Oxford: Oxford University Press).

García-Peñalosa, C. and K. Wälde (2000) 'Efficiency and Equity Effects of Subsidies to Higher Education', Oxford Economic Papers, vol. 52, pp. 702-722.

Gregory, B. (2009) 'Musing and Memories on the Introduction of HECS and Where to Next on Income Contingent Loans', Australian Journal of Labour Economics, vol. 12, no. 2, pp. 237-243.

Higgins, T. (2011) 'Income Support for Higher Education Through Income Contingent Loans', Economic Papers, vol. 30, no. 4, pp. 466-480. 
Higgins, T. and G. Withers (2009) 'Community Attitudes to Income Contingent Loans', Australian Journal of Labour Economics, vol. 12, no. 2, pp. 217-236.

Ionescu, F. (2008) 'Consolidation of Student Loan Repayments and Default Incentives', The B.E. Journal of Macroeconomics, vol. 8, article 22.

Ionescu, F. (2009) 'The Federal Student Loan Program: Quantitative Implications for College Enrolment and Default Rates', Review of Economic Dynamics, vol. 12, pp. 205231.

Ionescu, F. (2011) 'Risky Human Capital and Alternative Bankruptcy Regimes for Student Loans', Journal of Human Capital, vol. 5, pp. 153-206.

Kocherlakota, N. (2010) The New Dynamic Public Finance (Princeton: Princeton University Press).

Le Grand, J. (1991) Equity and Choice, (London: HarperCollins Academic).

Nerlove, M. (1975) 'Some Problems in the Use of Income Contingent Loans for the Finance of Higher Education', Journal of Political Economy, vol. 83, pp. 157-183.

Salanié, B. (2011) The Economics of Taxation, (Cambridge, Massachusetts: The MIT Press).

Shen, H. and A. Ziderman (2009) 'Student Loans Repayment and Recovery: International Comparisons', Higher Education, vol. 3, pp.315-333. 